\section{RANCANG BANGUN ALAT/MESIN ROL PRES CETAK LABEL KULIT}

Oleh : Asmongin, Supriyadi

\section{ABSTRACT}

Design of preparation roll press stamping machine for leather was carried out to produce machine, that can be used for stamping motives on leather grain sides, especially for vegetable tanned leather. This machine can help small industry or home industry to produce leather goods, such as belts, wallets, lady's bags and labels. The technical specification of the machine is : the diameter of stamping roll and feeding roll are about $60 \mathrm{~mm}$, the length of the rolls are about $200 \mathrm{~mm}$, roll rotation about $7.4 \mathrm{rpm}$. The electrical motor is about $0.5 \mathrm{HP}$; 1450 RPM; I Phase and the capacity of the machine is 1.272 meter/minute.

\section{INTISARI}

Rancang bangun alat/mesin rol pres cetak label kulit dilaksanakan untuk membuat mesin yang dapat mencetak motif timbul pada kulit, khususnya kulit samak nabati. Alat ini dapat membantu industri kecilindustri rumah tangga yang memproduksi barang-barang kerajinan dari kulit seperti ikat pinggang, dompet, tas wanita, dan merk/abel kulit untuk barangbarang kerajinan. Spesifikasi alat ini adalah : diameter rol cetak dan rol pembawa kulit 60 mm dan panjang $200 \mathrm{~mm}$, putaran 7.4 RPM, dijalankan oleh motor listrik 0.5 HP; 1450 RPM; 1 Phase. Kapasitas mesin adalah 1,272 meter/menit.

\section{PENDAHULUAN}

Pada saat ini keberadaan industri kecil di Indonesia merupakan kekuatan industri sebagai penghasil produk yang dapat dinilai sebagai potensi komoditi ekspor, sehingga perlu dikembangkan untuk menunjang produktivitasnya baik dari segi kualitas maupun kuantitasnya.

Salah satu bentuk pengembangan industri kecil yang mempunyai ciri khas padat karya adalah penyediaan sarana berupa alat/mesin sederhana yang dapat menunjang kemampuan industri kecil tersebut, untuk meningkatkan produksinya tanpa mengurangi jaminan kualitasnya.

Untuk membantu industri kecil khususnya perajin kulit yang mempro-duksi barang-barang kerajinan seperti ikat pinggang, dompet, asesoris lain serta label/ merk yang diberi motif sistem cetak dalam melakukan proses pencetakan motif perlu dibuat perekayasaan "Alat Rol Pres Cetak" yang dapat dioperasikan baik secara manual maupun elektrik, serta dapat menjamin memberi hasil pengecapan yang baik dan stabil.
Tujuan dari rancang bangun alat rol pres cetak label kulit ini diharapkan dapat membantu industri kecil (khususnya perajin kulit) dalam meningkatkan produksinya baik dari segi kualitas maupun kuantitasnya.

\section{Tinjauan Pustaka :}

Prinsip dasar dari kerja alat/mesin Rol Pres Cetak Label Kulit adalah mencetak motif pada permukaan kulit dengan jalan melewatkan lembaran kulit diantara 2 (dua) rol yang berputar berlawanan arah.

Rol dipasang berjajar vertikal, satu rol berfungsi sebagai rol penggerak (rol pendukung) kulit dan rol yang lain berfungsi sebagai rol pencetak motif. Rol pencetak motif dilengkapi dengan lapisan grafir dengan motif tertentu.

Rol penggerak dihubungkan dengan roda penggerak melalui alat transmisi (roda gigi) dan roda penggerak dapat digerakkan (diputar) secara manual atau secara elektrik.

Celah diantara 2 (dua) rol tersebut dapat diatur dengan jalan mengatur rol pencetak sedemikian rupa tergantung dari tebal kulit yang akan di pres cetak (pustaka :3).

Untuk menghindari friksi yang dapat mempengaruhi hasil pengecapan maka pada as rol harus dipasang bantalan (bearing). Kecepatan putar dari rol terutama untuk pekerjaan pengecapan dapat diambil kira-kira $7 \mathrm{rpm}$.

Untuk diameter rol antara $50 \mathrm{~mm}-80 \mathrm{~mm}$, panjang rol dapat diambil sekitar $200 \mathrm{~mm}-500 \mathrm{~mm}$ dengan pertimbangan bahwa pada saat diputar rol tidak goyang (pustaka : 2).

Menurut "ASSAB TOOL STEELS" jenis logam khusus untuk stempel (alat pengecapan) adalah No. 718 (sukar diperoleh di pasaran). Jenis lain yang dapat menggantikan No. 718 adalah DF-2. Sedang jenis logam rol dan "gear" (roda gigi) adalah "ASSAB MACHINERY MACHINE" 705 dengan kandungan $\mathrm{C}=0,35 \%$, $\mathrm{Cr}=1,40 \%, \mathrm{Ni}=1,40 \%, \mathrm{Mo}=0,20 \%$ dan $\mathrm{Mn}=0,10 \%$ (pustaka : 1 ).

Dari hasil studi lapangan yang dilaksanakan di BBLM Bandung diperoleh data sebagai berikut :

a. Pada pengatur celah rol grafir, digunakan sistem pengaturan pada rol bagian atas dengan memakai ulir. Ukuran ulir menggunakan "MATRIX 20".

b. Karena rol bagian atas diberi sistem pengatur, maka untuk mempermudah penggantian rol grafir yang dihubungkan dengan roda gigi adalah rol bagian bawah.

c. Untuk menghindari terjadinya pergeseran pada saat bahan kulit dimasukkan pada celah antara dua rol, bahan kulit tersebut perlu diarahkan dengan bantuan "meja pengarah" atau "rol" yang diletakkan didepan dan sejajar dengan celah rol.

Vol. XII No. 24 Th. 1996/1997 
d. Ketinggian rol disesuaikan dengan tinggi siku operator, berkisar antara 80 - 100 . $\mathrm{cm}$. Hal ini dimaksudkan agar operator tidak cepat kelelahan.

e. Untuk pembuatan grafir pada rol digunakan mesin grafir dengan kedalaman grafir/ketebalan gambar cetak pada rol maksimum $3 \mathrm{~mm}$.

\section{METODE RANCANG BANGUN}

Rancang bangun alat/mesin rol pres label kulit dilakukan dalam beberapa tahapan yaitu :

1. Tahap studi pustaka

Tahap ini merupakan tahap mencari informasi atau data-data melalui buku-buku yang ada hubungannya dengan pembuatan rancang bangun alat/mesin rol pres cetak label kulit.

2. Tahap studi lapangan

Kegiatan pada tahap ini berupa survai (pengumpulan data), konsultasi ke Balai Besar Logam dan Mesin di Bandung dan ke instansi serta industri-industri yang terkait.

3. Tahap rancang bangun

Pada tahap ini dilakukan sampai pembuatan gambar teknik dan penyusunan cara kerja alat/mesin.

\section{RANCANG BANGUN ALAT/MESIN ROL PRES CETAK LABEL KULIT}

Prinsip kerja dari alat/mesin rol pres cetak label kulit adalah mencetak motif pada permukaan kulit dengan jalan melewatkan lembaran kulit diantara 2 (dua) rol yang berputar berlawanan arah.

Rol dipasang berjajar vertikal, satu rol berfungsi sebagai penggerak (rol pendukung) kulit, dan rol yang lain berfungsi sebagai rol pencetak motif. Rol penggerak dihubungkan dengan roda penggerak melalui alat transmisi (roda gigi) dan roda penggerak dapat digerakkan (diputar) secara manual atau elektrik.

Adapun unit kelengkapan alat/mesin rol pres cetak label kulit ini terdiri dari : Body mesin, Rol penggerak (rol pendukung), Rol pencetak (rol grafir), Bantalan (boss), Stang pegas penekan, Ulir penahan bawah dan Stang roda penggerak.

1. Perancangan body mesin

Body mesin dibuat dari baja profil U ukuran $12 / 6 \mathrm{~cm}$.

Adapun ukuran body : panjang $=60 \mathrm{~cm}$; lebar $=50 \mathrm{~cm}$; tinggi $=130 \mathrm{~cm}$.

2. Perancangan rol penggerak

Rol penggerak dibuat dari bahan baja standar "ASSAB MACHINERY MACHINE" dengan ukuran : diameter $=60 \mathrm{~mm}$; panjang $=200 \mathrm{~mm}$.
3. Perancangan rol pencetak (rol grafir)

Rol pencetak (rol grafir) berfungsi sebagai rol pencetak motif. Bahan yang dipakai : baja standar "ASSAB MACHINERY MACHINE".

Ukuran : diameter $=30 \mathrm{~mm}$, dan panjang $=200 \mathrm{~mm}$.

Ring rol grafir, bahan yang digunakan baja dengan ukuran :

- motif naga : lebar $=35 \mathrm{~mm}$, diameter dalam $=30 \mathrm{~mm}$, diameter luar $=60$ $\mathrm{mm}$.

- motif BBKKP : lebar $=35 \mathrm{~mm}$, diameter dalam $=30 \mathrm{~mm}$, diameter luar = $60 \mathrm{~mm}$.

4. Bantalan untuk rol penggerak dan rol pencetak

Bahan : dari brons (kuningan) dengan ukuran :

tebal $=70 \mathrm{~mm}$, lebar $=45 \mathrm{~mm}$, diameter lubang as $=23 \mathrm{~mm}$

5. Stang pegas penekan (untuk mengatur pengepresan)

Diameter stang $=75 \mathrm{~mm}$, tebal $=20 \mathrm{~mm}$, diameter ulir $=3 / 4$ inchi, dan panjang ulir $=140 \mathrm{~mm}$.

6. Ulir penahan bawah (pada stang pegas)

Diameter $=3 / 4$ inchi, panjang $=75 \mathrm{~mm}$

7. Stang roda penggerak

Dilengkapi dengan handel pemutar dan lubang V-belt.

Bahan = baja tuang, diameter $=320 \mathrm{~mm}$.

8. Kelengkapan komponen yang lain :

a. Pulley roda penggerak : berfungsi sebagai penggerak rol secara manual, juga penerima transmisi dari putaran dari gear box.

Bahan : baja tuang, diameter $=308 \mathrm{~mm}$, tebal $=38 \mathrm{~mm}$.

b. Pulley gear box :

- dihubungkan dengan motor, bahan $=$ baja tuang, diameter $=125 \mathrm{~mm}$.

- dihubungkan dengan roda penggerak, bahan = baja tuang, diameter $=70$ $\mathrm{mm}$.

c. Roda gigi transmisi : bahan = baja standar ASSAB MACHINERY MACHINE.

d. V-belt : type A sebanyak 2 (dua) buah. Ukuran = 35 dan 62 inchi

e. Gear box : model WPA, type 70 .

f. Motor penggerak : 1 phase 220 volt, $1 / 2 \mathrm{HP}, 1450 \mathrm{rpm}$.

g. Sakelar 4/8 Ampere dan tombol ON/OFF.

h. Celah pembatas : berfungsi untuk mengarahkan lembaran kulit yang akan dipres supaya tepat di daerah pengepresan. 
Bahan : plat baja.

i. Tutup pulley : bahan dari plat besi $2 \mathrm{~mm}$.

\section{A. Perhitungan putaran pada rol penggerak (rol pendukung)}

1. Transmisi dari motor ke gear box

- motor $=1450 \mathrm{rpm}$

- diameter pulley motor $(\mathrm{R} 1)=100 \mathrm{~mm}$

- diameter pulley I gear box (R2) $=125 \mathrm{~mm}$.

- putaran pulley gear box $=\stackrel{R 1}{ } \times 1450 \mathrm{rpm}$

$$
\begin{aligned}
& \text { R2 } \\
& 100 \times 1450 \mathrm{rpm} \\
& 125 \\
& =1160 \mathrm{rpm}
\end{aligned}
$$

2. Tranmisi gear box ke roda penggerak (pulley roda penggerak)

- ratio gear box $=1: 10$

$$
\text { putaran gear box menjadi }=-1160 \quad=116 \mathrm{rpm}
$$$$
10
$$

- diameter pulley gear box $\Pi=70 \mathrm{~mm}$

- diameter roda penggerak $=300 \mathrm{~mm}$.

$$
\begin{aligned}
\text { - putaran roda penggerak } & =\frac{70}{300} \times 116 \mathrm{rpm} \\
& =27 \mathrm{rpm}
\end{aligned}
$$

3. Tranmisi dari roda penggerak ke rol penggerak melalui roda gigi.

- roda gigi utama (yang dihubungkan dengan rol penggerak) jumlah gigi $(\mathrm{Z} 1)=66$

- roda gigi perantara (yang dihubungkan dengan roda penggerak) jumlah gigi $(\mathrm{Z} 2)=18$

perputaran rol penggerak $=\frac{\mathrm{Z} 2}{\mathrm{Z} 1} \times$ rpm roda penggerak

$$
\begin{aligned}
& =\frac{18}{66} \\
& =\quad 7,4 \mathrm{rpm}
\end{aligned}
$$

Jadi kecepatan putar rol penggerak dalam proses cetak diperkirakan sekitar = $7,4 \mathrm{rpm}$.

\section{B. Perhitungan kecepatan pres cetak}

- kecepatan putaran rol penggerak $=7,4 \mathrm{rpm}$

- diameter rol penggerak $=60 \mathrm{~mm}$

- Keliling rol penggerak $=3,14 \times 60 \mathrm{~mm}=188 \mathrm{~mm}$

Kecepatan pres cetak $=$ keliling $\times$ kecepatan ro

$=188 \mathrm{~mm} \times 7,4 /$ menit

$=1272 \mathrm{~mm} /$ menit

$=1,272 \mathrm{~m} /$ menit

Jadi dalam rancang bangun ini kapasitas alat/mesin kira-kira 1 (satu) buah sabuk per menit.

\section{HASIL RANCANG BANGUN ALAT/MESIN ROL PRES CETAK LABEL KULIT}

Hasil rancang bangun alat/mesin rol pres cetak label kulit mempunyai spesifikasi sebagai berikut :

1. Body mesin dibuat dari baja profil $\mathrm{U}$, ukuran $12 / 6 \mathrm{~cm}$.

Dengan ukuran : $p=60 \mathrm{~cm} ; 1=50 \mathrm{~cm}$; tinggi $=130 \mathrm{~cm}$

2. Rol penggerak (rol pendukung) : bahan baja standar "ASSAB MACHINERY MACHINE" dengan $\emptyset=60 \mathrm{~mm}$, dan panjang $=200 \mathrm{~mm}$.

3. Rol pencetak (rol grafir) terdiri :

- rol penahan : bahan baja standar "ASSAB MACHINERY MACHINE" ukuran : $\varnothing=30 \mathrm{~mm}, \mathrm{p}=200 \mathrm{~mm}$

- ring rol grafir : bahan baja tuang, ukuran :

* motif Naga : $\varnothing$ dalam $=30 \mathrm{~mm} ; \varnothing$ luar $=60 \mathrm{~mm} ; 1=35 \mathrm{~mm}$

* motif BBKKP : $\varnothing$ dalam = $30 \mathrm{~mm}$; $\varnothing$ luar $=60 \mathrm{~mm} ; 1=35 \mathrm{~mm}$

4. Bantalan (boss) : bahan dari brons (kuningan)

ukuran : tebal $=70 \mathrm{~mm} ; 1=45 \mathrm{~mm}$; $\varnothing$ lubang as $=23 \mathrm{~mm}$

5. Stang pegas : $\varnothing$ stang $=75 \mathrm{~mm}$; tebal stang $=20 \mathrm{~mm}$ 
$\emptyset$ ulir $=3 / 4$ inchi; $p=140 \mathrm{~mm}$

6. Ulir penahan stang pegas : $\varnothing=3 / 4$ inchi; $p=75 \mathrm{~mm}$

7. Stang roda penggerak bahan baja tuang; $\varnothing=320 \mathrm{~mm}$.

8. Kelengkapan komponen yang lain :

- pulley roda penggerak : bahan baja tuang; $\varnothing=308 \mathrm{~mm} ; \mathrm{t}=38 \mathrm{~mm}$

- pulley gear box 2 (dua) buah : bahan baja tuang; $\emptyset=125 \mathrm{~mm}$ dan $70 \mathrm{~mm}$

- roda gigi tranmisi : bahan baja standar "ASSAB MACHINERY MACHINE"

- V-belt type A : 2 buah, ukuran 35 dan 62 inchi

- gear box; model WPA; type : 70; ratio : $1: 10$; No. seri : 950117

- sakelar 4/8 A; tombol ON/OFF

- celah pembatas : bahan plat baja

- tutup pulley : bahan plat baja $2 \mathrm{~mm}$

Sedang cara kerja alatmesin rol pres cetak label kulit dari hasil rancang bangun adalah sebagai berikut :

a. Persiapan terlebih dahulu kulit yang akan dikerjakan.

b. Pasang ring rol grafir sesuai dengan gambar motif yang diinginkan pada rol penekan dengan membuka blok bantalan as dibagian depan.

c. Atur batas ukuran/plat dinding pengarah jalannya kulit sesuai dengan ukuran lebar kulit.

d. Atur tekanan antara rol pendukung dengan rol grafir, dengan memutar ulir dari stang pegas penekan kiri kanan.

e. Pasang stecker listrik pada stop kontak 220 Volt.

f. Letakkan kulit pada celah antara rol pendukung dan rol penekan kulit, kemudian injak pedal off/on, motor listrik akan berputar, kulit akan berjalan diantara rolrolnya sambil pengepresan berlangsung sehingga menghasilkan gambar motif pada permukaan kulit sesuai dengan gambar motif pada ring rol grafir.

g. Jika hasil gambar motif kurang atau terlalu tebal/tajam maka atur kembali stang pegas penekan.

h. Apabila selesai pengepresan, maka injakan pada pedal off/on dilepas, mesin/ alat akan berhenti dengan sendirinya.

i. Atur kembali pemasangan ring rol grafir, pengatur batas ukuran/plat dinding pengarah kulit dan tekanan apabila jenis dan ukuran kulit diganti.

\section{KESIMPULAN}

Dari hasil rancang bangun alat/mesin rol pres cetak label kulit dapat diambil kesimpulan bahwa :

1. Alat rol pres cetak label kulit ini dapat dioperasikan secara fleksibel dalam arti dapat dioperasikan secara manual dan secara elektrik.

2. Bahan-bahan alat rol pres cetak label kulit ini sangat mudah diperoleh di pasaran (dalam negeri), demikian juga dengan konstruksi dari alat ini sangat sederhana.

3. Desain dari alat/mesin pres cetak label kulit sangat sederhana sehingga untuk perakitan, perbaikan dan penggantian suku cadang dari alat ini mudah dilakukan oleh industri kecil pengguna alat/mesin tersebut.

4. Berdasarkan data perhitungan alat ini mampu mencetak/mengepres kulit 1,272 $\mathrm{m} /$ menit, dengan ukuran lebar maksimal $35 \mathrm{~mm}$

\section{DAFTAR PUSTAKA}

1. Tabel "ASSAB TOOL" dan "ASSAB MACHINERY STEELS".

2. C.H. Jensen, Engineering Drawing and Design, Mc. Graw Hill.

3. Soegiyanti, dkk. Elemen Mesin-Mesin, Proyek Polyteknik Mekanik Swiss-Institut Teknologi Bandung, 1978. 


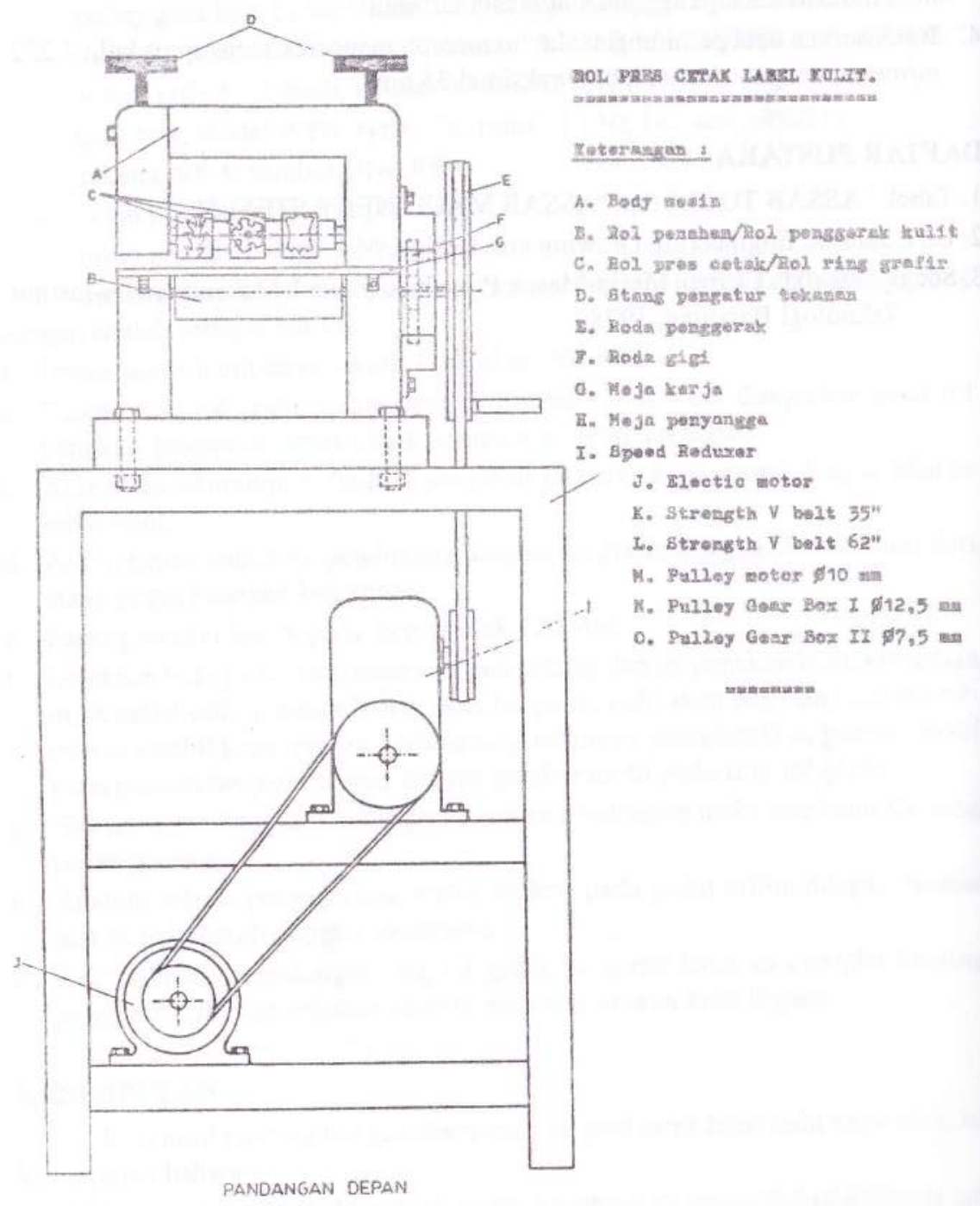

